\title{
Effects of elements or compound preexposure on conditioned taste aversion as a function of retention interval
}

\author{
ROBERTO ÁLVAREZ and MATÍAS LÓPEZ \\ Universidad de Oviedo, Oviedo, Spain
}

\begin{abstract}
The effects of element or compound preexposure and retention interval were examined in three experiments with the taste-aversion paradigm. In Experiment 1, preexposure to the elements of a compound flavor produced less latent inhibition to the compound than did preexposure to the compound itself when a 1-day preexposure-conditioning interval was used. However, preexposing the elements or the compound resulted in equivalent latent inhibition effects when a 21-day retention interval was used. In Experiment 2, a similar pattern of results was observed when the conditioning-test interval was manipulated. Experiment 3 explored the effect of element or compound preexposure when preexposure and test were carried out in different contexts. Attenuated latent inhibition following preexposure to the elements was found when preexposure and test were carried out in the same context. In contrast, preexposure to the elements resulted in as much latent inhibition as did preexposure to the compound when the context was switched from preexposure to testing. The implications of these findings for a retrieval-oriented view of latent inhibition are discussed.
\end{abstract}

It is well established that nonreinforced exposure to a conditioned stimulus (CS) prior to conditioning reliably retards the acquisition of conditioned responding to that CS. This phenomenon has been observed in a variety of experimental preparations and has been named latent inhibition (e.g., Lubow, 1973, 1989). The conventional interpretation of such an interference effect is that repeated presentation of the to-be-conditioned stimulus before conditioning trials markedly impairs acquisition, and a variety of perceptual and associative mechanisms such as reduction of attention, loss of associability, learning of inattention, and habituation of rehearsal have been proposed to account for the resulting disruption (see, e.g., Lubow, Weiner, \& Schnur, 1981; Mackintosh, 1975; Pearce \& Hall, 1980; Wagner, 1978, 1981).

Recent evidence, however, argues against the traditional explanations of the stimulus preexposure effect in terms of a failure of acquisition of information or a learning deficit. In a number of systematic studies, using the conditioned taste aversion procedure, Kraemer and his colleagues (e.g., Kraemer, Hoffman, \& Spear, 1988; Kraemer \& Ossenkopp, 1986; Kraemer \& Roberts, 1984; Kraemer \& Spear, 1992; see also Bakner, Strohen, Nordeen, \& Riccio,

This research was supported by Grant PB 92-1019 from the DGICYT (M.E.C., Spain) to M.L.R., and by a BFPI grant to R.A.G. We thank Vincent M. LoLordo for his helpful comments, and Concepción Paredes for her assistance in conducting the experiments. Correspondence concerning this article should be addressed to either M. López or R. Álvarez, Departamento de Psicologia, Universidad de Oviedo, C/Aniceto Sela $\mathrm{s} / \mathrm{n}, 33005$ Oviedo, Spain.

- Accepted by previous editor, Vincent M. LoLordo
1991; and Batsell \& Best, 1992) found a "release" from the latent inhibition effect (i.e., a stronger taste aversion) associated with delayed testing. For example, Kraemer and Roberts (1984) examined the effects of nonreinforced exposure to either the to-be-conditioned flavor (saccharin) or a different flavor (apple juice), by testing subjects either 1 or 21 days after conditioning. When the saccharin aversion was tested after 1 day, both forms of preexposure attenuated the conditioned aversion. However, after a 21 -day interval, preexposure to saccharin still produced an attenuated aversion, whereas prior experience with apple juice did not reduce the magnitude of the saccharin aversion. Similar results after 1- and 21-day intervals have been reported by Kraemer, Randall, and Carbary (1991) with the conditioned emotional response procedure. All these studies support a retrieval failure interpretation of the latent inhibition effect. It has been argued (e.g., by Kraemer \& Roberts, 1984) that preexposure and conditioning episodes are represented as independent memories. Therefore, when individuals are tested soon after conditioning, the preexposure episode could interfere with the retrieval of the memory for the conditioning phase. With a longer retention interval, the ability of the preexposure memory to interfere with the retrieval of the conditioning memory would decline because the memory of the CS alone is lost more readily than the memory of the CS-unconditioned stimulus (US). Consequently, CS aversion would appear.

Bouton (1991, 1993; see also Bouton \& Brooks, 1993) has also favored a retrieval account of latent inhibition. The account emphasizes that interference effects occur at the level of performance rather than learning. Thus, in a latent inhibition experiment, information from both the preexposure and the conditioning phases would be stored 
in memory, and performance might then be determined at any point by which of the available memories is retrieved. The view also assumes that the retrieval of a preexposure episode following conditioning would depend critically on the similarity between the conditions present at time of retrieval and those present at time of preexposure experience. In accordance with this view, latent inhibition appears to be attenuated when a context switch (see, e.g., Bouton \& Brooks, 1993; Gordon \& Weaver, 1989; Hall \& Channell, 1985) or a retention interval (see, e.g., Hall \& Minor, 1984; Kraemer \& Roberts, 1984; McIntosh \& Tarpy, 1977) occurs between preexposure and conditioning.

Given the provocative nature of the release from latent inhibition with delayed testing and its theoretical significance, in these experiments we analyzed the effects of preexposure to either a compound taste stimulus or its separate elements on later conditioning to the compound flavor as a function of retention interval. Conditioned aversions to a compound flavor were examined at 1 - and 21 -day preexposure-conditioning (Experiment 1) and conditioning-test (Experiment 2) intervals. Moreover, since the effects of CS preexposure depend importantly on context, in Experiment 3, we explored the effects of nonreinforced exposure to the elements or the compound on later conditioning to the compound when a context switch occurred between the preexposure and test phases.

\section{EXPERIMENT 1}

This experiment had two goals. The first was to analyze the effects of nonreinforced exposure to a compound flavor or to its separate elements on later aversion conditioning to the compound stimulus. Baker, Haskins, and Hall (1990), using a similar preparation, reported that preexposure to the compound flavor produced a stronger latent inhibition effect than did preexposure to its elements separately (see also Álvarez Gómez \& López Ramírez, 1993; López Ramírez \& Aguado Aguilar, 1992). These results have been interpreted as resulting from a generalization decrement between the preexposure and conditioning phases. From a perceptual view (see, e.g., Honey \& Hall, 1988, 1989; Rescorla, 1973), if a compound stimulus is perceived as being in some way different from its elements, a change from elements to compound between preexposure and conditioning should result in an attenuation of latent inhibition, relative to a control condition in which the compound stimulus is preexposed and conditioned.

The second goal was to assess the effects of a retention interval between the preexposure and conditioning phases. As in other paradigms (see Bouton, 1991, 1993), the passage of time may have important effects on latent inhibition. For example, it is well known that generalization gradients tend to flatten over time (for reviews, see Riccio, Ackil, \& Burch-Vernon, 1992, and Riccio, Richardson, \& Ebner, 1984), and this flattening has been interpreted as reflecting a process of forgetting in long-term memory (see, e.g., Spear, 1978; Thomas, 1981). If the precise attributes of stimuli are forgotten over time, extending the interval between preexposure and conditioning in a latent inhibition experiment should then increase the generalization of the preexposure effects when the to-be-conditioned stimulus differs in some way from the preexposed stimulus. Thus, an equivalent latent inhibition effect should be obtained no matter whether a compound flavor or its separate elements has been preexposed. We tested this hypothesis by preexposing the animals to a compound flavor or its elements separately and conditioning the compound either 1 day or 21 days later. For each retention interval, one group of subjects (Group COM) was preexposed to the compound flavor and the other one (Group ELE) received preexposure to the elements separately. A third group, the control group (Group CON), did not receive any preexposure. All the animals then received aversion conditioning to the compound solution, and then a test with the compound itself.

\section{Method}

Subjects. The subjects were 54 male Wistar rats, 120 days old at the start of the experiment and with a mean free-feeding weight of $384 \mathrm{~g}$ (range, $292-496 \mathrm{~g}$ ). The animals were kept on a waterdeprivation schedule throughout the experiment and had constant access to food. The experiment was conducted on consecutive days during the light portion of a 12:12-h light:dark cycle.

Apparatus and solutions. The rats were housed in individual standard home cages $(25 \mathrm{~cm}$ long, $24 \mathrm{~cm}$ wide, $15 \mathrm{~cm}$ high) of opaque polycarbonate plastic. The fluids were presented in calibrated $50-\mathrm{ml}$ polycarbonate centrifuge tubes equipped with stainless steel ball-bearing-tipped spouts. The drinking solutions were unflavored tap water, vinegar and coffee solutions with concentrations of $1 \% \mathrm{v} / \mathrm{v}$ and $1 \% \mathrm{w} / \mathrm{y}$, respectively, and a compound containing both flavors that was mixed so as to maintain the concentrations of the individual solutions. The solvent for all solutions was tap water. All intakes were recorded to the nearest $0.5 \mathrm{ml}$. The experimental context for preexposure, conditioning, and testing was a room different fron the colony room, illuminated weakly by a $60-\mathrm{W}$ bulb placed in a corner in the room. The amount of solution drunk by each animal was determined by weighing the centrifuge tubes before the beginning and after the end of each session. These scores were converted to milliliters drunk, assuming that the specific density of all solutions was 1.

Procedure. The rats were gradually adapted to a water-deprivation schedule over a period of 7 days. During that period, they received access to water in the drinking tubes for $30 \mathrm{~min}$ per day in their home cages. For the next 2 days, all animals were given access to $15 \mathrm{ml}$ of tap water in the experimental context. All animals drank all of the water within this daily period. Following this phase came the preexposure phase of the experiment, which lasted only 1 day.

The animals were divided into six groups for the preexposure day. Two groups (COM-1 and COM-21) were given two 30-min exposures to $10 \mathrm{ml}$ of the compound solution in the drinking tubes. Two other groups (ELE-1 and ELE-21) received exposures to the vinegar and the coffee solutions, separately. Half of the animals in each of these groups received a $30-\mathrm{min}$ exposure to $10 \mathrm{ml}$ of the vinegar solution and then a 30 -min exposure to $10 \mathrm{ml}$ of the coffee solution; for the remaining animals, this arrangement was reversed. The control groups (CON-l and $\mathrm{CON}-21$ ) received $30 \mathrm{~min}$ of access to $10 \mathrm{ml}$ of water for each exposure instead. The interval between the two exposures to the fluids was $5 \mathrm{~h}$ in all cases. 
Animals in the 1-day preexposure-conditioning intervalGroups COM-1, ELE-1, and CON-1 ( $n=8$ for each group) -were conditioned on the day following the preexposure phase, whereas the remaining animals-Groups COM-21, ELE-21, and CON-21 ( $n=10$ for each group)-were conditioned 21 days later. After the preexposure session, the animals in the 21-day retention interval condition received water ad lib in the home cages until 7 days prior to the beginning of the conditioning session, when they were again water deprived. During the conditioning session, all of the animals received $30 \mathrm{~min}$ of access to $10 \mathrm{ml}$ of the compound flavor, which was followed $10 \mathrm{~min}$ later by an intraperitoneal (i.p.) injection of $0.15 \mathrm{M} \mathrm{LiCl}$ solution $(10 \mathrm{ml} / \mathrm{kg}$ of body weight).

On the day following the conditioning session, all of the animals received a recovery day, on which they were given free access to water for $30 \mathrm{~min}$ in the home cages. On the next day, the rats received the test session, in which they were given a 10 -min access to the compound flavor.

\section{Results}

During the preexposure day, all animals drank all $10 \mathrm{ml}$ of the appropriate solution on each of the two exposures to the fluids. Likewise, on the conditioning day, all rats drank all $10 \mathrm{ml}$ of the compound solution.

Figure 1 shows the mean consumption of the compound flavor by the different groups on the test day. This figure suggests that the effect of the two preexposure procedures depended on the preexposure-conditioning interval; that is, animals preexposed to the elements separately and conditioned 1 day later (Group ELE-1) showed less latent

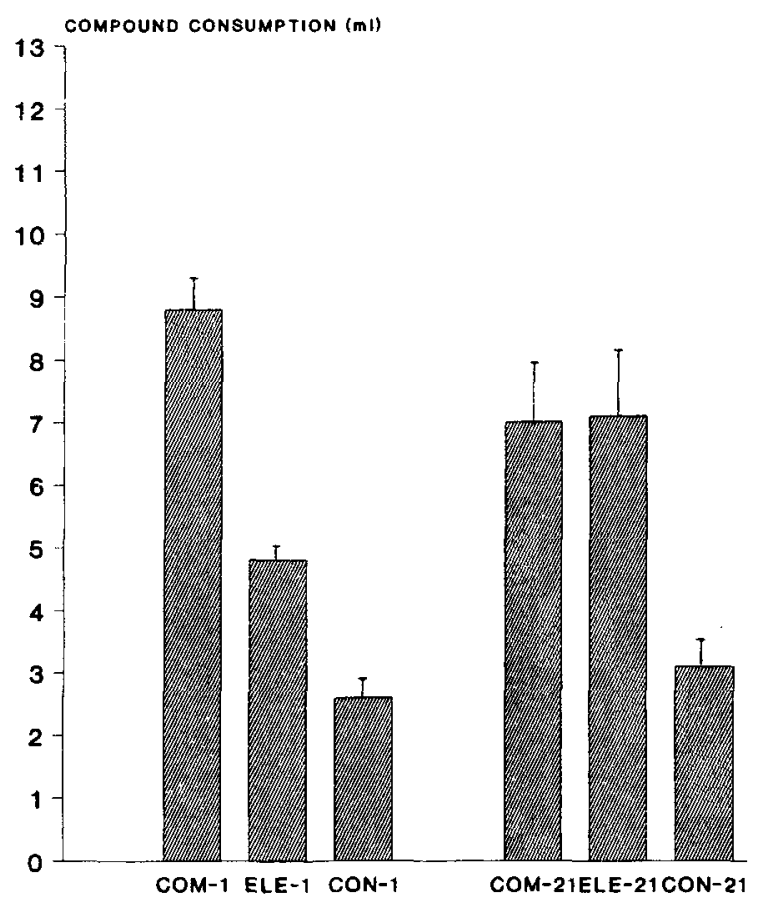

Figure 1. Experiment 1: Mean consumption of the compound flavor during the test day for each of the groups. Groups COM1 and COM-21 received preexposure to the compound flavor; Groups ELE-1 and ELE-21 received element preexposure; Groups CON-1 and CON-21 had no preexposure experience. inhibition than did animals in the compound preexposure group (Group COM-1). In contrast, the animals preexposed to the compound (Group COM-21) and those preexposed to the elements (Group ELE-21) showed a similar latent inhibition effect when a 21 -day retention interval was used.

A two-way analysis of variance (ANOVA; preexposure and retention interval) of the data on the test day revealed a significant effect of the preexposure factor $[F(2,48)=$ $23.5, p<.001]$, no effect of the retention interval $[F(1,48)=0.3, p>.5]$, and a significant interaction between these factors $[F(2,48)=3.8, p<.05]$.

Further post hoc Newman-Keuls comparisons ( $p<$ .05 ) revealed that animals in Group COM-1 drank more than did those in Group ELE-1 or those in Group CON-1. On the other hand, animals in Group COM-21 and those in Group ELE-21 drank comparable amounts and both drank significantly more than did Group CON-21. The analyses also revealed no significant differences between Groups COM-1 and COM-21 or between Groups CON-1 and CON-21, but Group ELE-1 drank significantly less than did Group ELE-21.

\section{Discussion}

This experiment yielded two main results. First, it showed that preexposure to a compound flavor or preexposure to its separate elements reduces later conditioning of a toxicosis-based aversion to the compound. That is, a reliable latent inhibition effect was obtained following preexposure to either the elements or the compound. Second, when a I-day preexposure-conditioning interval was used, preexposure to the elements produced less latent inhibition to the compound stimulus (i.e., more conditioned aversion) than did preexposure to the compound itself. Thus, it appears that the change from elements to compound between preexposure and conditioning reduced transfer between these phases, thus attenuating latent inhibition. However, such an effect did not occur when a 21 day retention interval was introduced.

The pattern of results in this experiment replicates and extends prior findings by Baker et al. (1990) and by López Ramírez and Aguado Aguilar (1992), thus providing support for a perceptual interpretation of preexposure effects in latent inhibition arising from a stimulus change between preexposure and conditioning. The reduced transfer of the effects of preexposure observed in the element exposure condition suggests that the animals perceived a difference between the compound and its elements and is thus consistent with the accounts that conceive a compound stimulus as having properties different from those of its constitutive elements (e.g., Rescorla, 1973; Siegel, 1969). On the other hand, the results obtained in the 21 day retention interval condition argue for an interactive effect of time and preexposure factors in latent inhibition. It could be concluded from this experiment that memory for the details of the preexposure experience were reduced with time and that, as a result, generalization from preex- 
posure to conditioning increased when the interval between the preexposure and conditioning phases was extended to 21 days.

\section{EXPERIMENT 2}

The results of Experiment 1 indicate that preexposure to the elements of a compound flavor resulted in a weaker latent inhibition effect than did preexposure to the compound itself, but only when there was a short interval between preexposure and conditioning. By contrast, with a long retention interval, latent inhibition was equivalent with both preexposure procedures. Before accepting an interpretation of this effect as a manifestation of an associative deficit depending on the extent of generalization between preexposure and conditioning, an alternative account should be considered. From a retrieval perspective, it could be argued that on test the preexposure and conditioning memories are compared. With a short preexposuretest interval, the memory of the element preexposure interferes less with the memory of the conditioning episode because of generalization decrement, and thus an attenuated latent inhibition is observed in the element preexposure condition. By contrast, with a long retention interval, the memory of element preexposure becomes more like that of compound preexposure, and thus the two preexposure treatments produce equivalent latent inhibition. In a second experiment, we tested this hypothesis by manipulating the conditioning-to-test interval.

The procedure for Experiment 2 paralleled that of Experiment 1 , except that the effect of a retention interval between conditioning and test phases was assessed. Rats were exposed either to a compound of two flavors or to the two flavors separately, and on the next day, all the animals received an aversion conditioning session with the compound flavor. On the day following the conditioning session, half of the animals in each preexposure condition received the test, whereas the remaining animals were tested 21 days later.

\section{Method}

Subjects. The subjects were 72 male Wistar rats with an age of $120-150$ days at the beginning of the experiment and a mean weight of $350 \mathrm{~g}$ (range, $294-464 \mathrm{~g}$ ). They were maintained under conditions identical to those described in Experiment 1.

Apparatus and solutions. The apparatus and solutions were the same as those employed in Experiment 1.

Procedure. Except where otherwise stated, all procedural details were similar to those of Experiment 1 . Over a period of 7 days, the subjects were adapted to a water-deprivation schedule under which they received a $30-\mathrm{min}$ access to water each day at $1100 \mathrm{~h}$. On the next 2 days, the rats had access to $15 \mathrm{ml}$ of water in the room in which preexposure, conditioning, and testing took place.

The animals were divided into six groups $(n=12)$ for the preexposure phase of the experiment, which lasted 2 days. On each of these days, animals in the compound preexposure condition, Groups COM-1 and COM-21, were given access to $15 \mathrm{ml}$ of the vinegarcoffee solution in the drinking tubes. The element preexposure groups, ELE-1 and ELE-21, received separate 15-ml exposures to the vinegar and coffee solutions on consecutive days, with the order of presentation counterbalanced. During this phase, subjects in the control groups, CON-1 and CON-21, drank $15 \mathrm{ml}$ of tap water in each daily exposure. In all cases the tubes were removed after $30 \mathrm{~min}$ had elapsed. Conditioning, which took place on the day following the preexposure phase, consisted of the presentation of $15 \mathrm{ml}$ of the compound solution for $30 \mathrm{~min}$, followed immediately by an i.p. injection of $\mathrm{LiCl}(.15 \mathrm{M} ; 10 \mathrm{ml} / \mathrm{kg}$ body weight).

Groups COM-1, ELE-1, and CON-1 were tested on the day after the conditioning session. The test consisted of a 10 -min presentation of the compound flavor in the experimental context. Groups COM21 , ELE-21, and CON-21 were tested 21 days after the conditioning session. Animals in the 21-day retention interval groups were given water ad lib in the home cages up to 7 days before testing, when they were again water deprived.

\section{Results}

During the preexposure phase, all animals drank all $15 \mathrm{ml}$ of the appropriate solution in each of the two exposures to the fluids. Likewise, on the conditioning day, all animals drank the $15 \mathrm{ml}$ of compound solution.

Figure 2 displays the mean consumption of the compound flavor by the different groups during the test day. This figure suggests that the consumption by rats in Group ELE-1 was lower than that of rats in Group COM-1, whereas in the 21-day interval condition, the levels of Groups COM-21 and ELE-21 were similar. The figure also shows that all the groups that were given nonreinforced exposure to the flavors drank more than the control

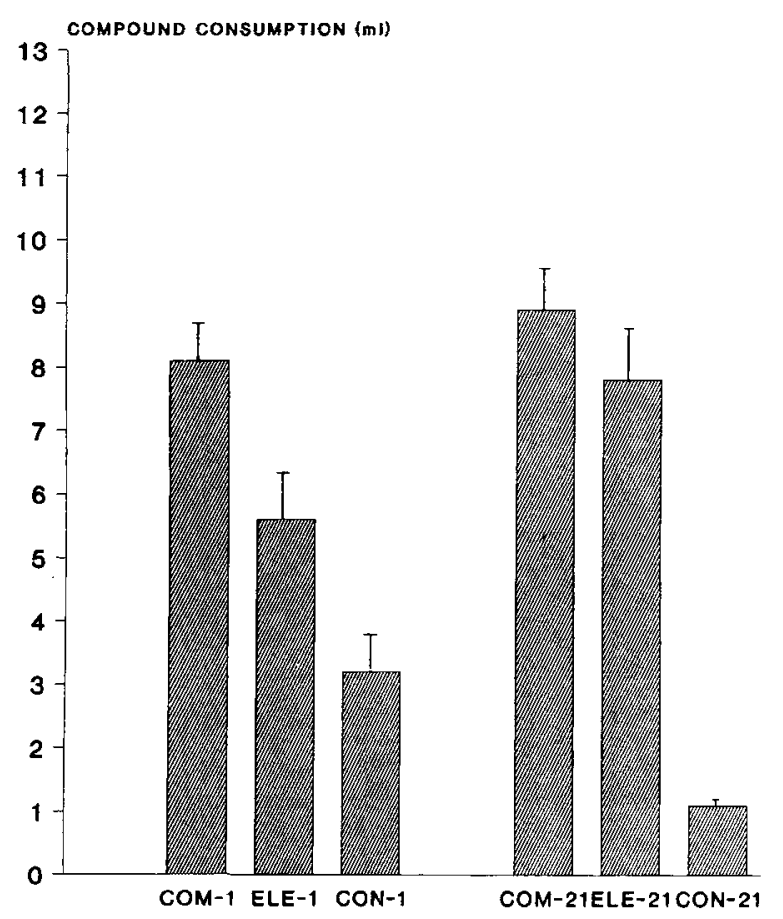

Figure 2. Experiment 2: Mean consumption of the compound flavor during test session for the different groups. Groups COM1 and COM-21 received preexposure to the compound flavor; Groups ELE-1 and ELE-21 received preexposure to the elements separately; Groups $\mathrm{CON}-1$ and $\mathrm{CON}-21$ did not receive exposure experience. 
groups during the test day. This description was confirmed by a two-way ANOVA (preexposure and retention interval) conducted on consumption during the test session. Although the analyses revealed no effect of the retention interval $[F(1,66)=0.26, p>.05]$, there was a significant effect of preexposure $[F(2,66)=44.5, p<$ $.001]$, and more important, a significant interaction between preexposure and retention interval $[F(2,66)=5.87$, $p<.01]$.

Further between-groups Newman-Keuls comparisons $(p<.05)$ revealed that Groups COM-21 and ELE-21 drank comparable amounts, and that both drank significantly more than did Group CON-21. However, it was found that Group ELE-1 drank significantly less than Group COM-1, although both groups drank significantly more than Group CON-1. The analyses also revealed no significant differences between Groups COM-1 and COM-21. Finally, significant differences were found between Groups ELE-1 and ELE-21 and between Groups CON-1 and CON-21.

\section{Discussion}

The pattern of results in this experiment replicates that obtained in Experiment 1 when the conditioning-test interval was varied. As in the former experiment, in this experiment exposure to the separate elements of a compound flavor prior to the conditioning of the compound attenuated the magnitude of latent inhibition, relative to a group in which the compound flavor was preexposed and conditioned. However, this effect emerged only when 1 day conditioning-test interval was used. In contrast, at the 21-day retention interval, a strong latent inhibition effect was observed in both the element preexposed group and the compound preexposed group.

As with the results in Experiment 1 , an explanation involving both a stimulus generalization decrement mechanism and the effects of the passage of time on memory traces may well explain the test data from the present experiment. It could be argued that rats retrieve the memories of preexposure and conditioning episodes during testing and integrate them, and that with the long retention interval after preexposure the memory of separate element presentation becomes more like that of compound presentation. Specifically, the equivalent latent inhibition effect obtained in this experiment with a 21-day conditioning - test interval following preexposure to the elements or to the compound suggests that after this interval the memory traces of the flavors experienced during the preexposure phase are similar under both preexposure conditions. Thus, with the passage of time, the animals forget the characteristics of the preexposed stimuli, so that the generalization between the memories of the preexposure episode and the conditioning episode would be increased.

In conclusion, the results obtained in Experiment 2, like those of Experiment 1 , could well be accommodated by an account of latent inhibition which incorporates perceptual and retrieval processes. The findings in these experiments appear to indicate that on test, animals compare the preexposure and conditioning memories and that the passage of time facilitates the generalization between the preexposure and conditioning experiences.

\section{EXPERIMENT 3}

As mentioned in the general introduction, Bouton has also argued for a retrieval view of latent inhibition which emphasizes an interference effect that would occur at the level of performance rather than learning (e.g., Bouton, 1991, 1993; Bouton \& Brooks, 1993). A prediction derived from this account is that manipulations of context and retention interval should have similar effects in a latent inhibition experiment. The view assumes that the passage of time itself produces a gradually changing context and that memories of nonreinforcement may be especially dependent on context for retrieval. In order to test these assumptions, in this third experiment we explored the effect of a context switch introduced shortly after preexposure on the latent inhibition expected following element or compound preexposure.

One group received preexposure experience with the compound flavor in one context (A). Following aversion conditioning to the compound in the home cages, half of the animals in this group were tested in Context $\mathrm{A}$, and the other half received the test in an alternative context (B). Another pair of groups received identical treatment, except that they were exposed to the elements of the compound separately during the preexposure phase. Finally, control groups did not receive any preexposure to the flavors. From a retrieval view of latent inhibition, like that proposed by Bouton, if a context switch between preexposure and testing has the same effects as extending the retention interval, we should expect an attenuation of the latent inhibition effect following preexposure to either a compound flavor or its separate elements.

\section{Method}

Subjects. The subjects were 46 male Wistar rats from the same stock used in the previous experiments. The rats were $120-150$ days old at the start of the experiment and had a mean weight of $346 \mathrm{~g}$ (range, $277-425 \mathrm{~g}$ ). The housing and maintenance conditions were the same as in the previous experiments.

Apparatus and solutions. The cages and centrifuge tubes of Experiments 1 and 2 were again used. In addition to the experimental context (A) employed in Experiments 1 and 2, a second context (B) was now provided by placing the animals in their home cages in a different room of the laboratory. This context was made distinctive by a background noise (click) and strong illumination. The solutions were the same as those employed in previous experiments.

Procedure. Except where otherwise stated, all procedural details of the experiment were identical to those of the previous experiments. Initially, the rats were adapted to a water-deprivation schedule consisting of a daily $30-\mathrm{min}$ period of access to water at $1100 \mathrm{~h}$. Over the last 2 days of the water-deprivation schedule, the animals were given a daily $30-\mathrm{min}$ access to water in Contexts $A$ and $B$ in alternating sessions. Then the preexposure phase of the experiment began.

The animals wcre divided into three groups for the preexposure phase, which lasted 4 days. The compound preexposure group received exposures to the vinegar-coffee compound solution (Group 
COM) and tap water on alternating days in Contexts A and B. Half of the animals in this group received the compound solution in Context A on Days 1 and 3, and tap water in Context B on Days 2 and 4. The other half received the compound solution in Context $A$ on Days 2 and 4, and the water in Context $B$ on Days 1 and 3 . The element preexposure group (Group ELE) was exposed to the vinegar and coffee solutions in Context $A$, and to tap water in Context B on alternating days, with order of presentation of the flavors counterbalanced. Finally, the control group (Group CON) received tap water on each of the 4 days. On each of the preexposure days, all animals received access to $15 \mathrm{ml}$ of the appropriate solution at $1100 \mathrm{~h}$. The tubes were removed after 30 min unless the animals had not consumed the $15 \mathrm{ml}$ of solution; in such cases, the tubes were left on the cages until all the solution had been consumed. This was necessary only on Day 1. On subsequent days, all of the animals drank the $15 \mathrm{ml}$ of solution within $30 \mathrm{~min}$.

Three aspects of the preexposure procedure are worth noting First, all animals had the same exposure experience with the appropriate solutions in Context A. Second, throughout the preexposure phase, the rats were given alternating sessions in the two contexts to equate familiarity with them. Finally, all animals received water in Context $\mathbf{B}$, which was the test context for animals tested in a different context from that of preexposure.

On the next day, the aversion conditioning session took place in the colony room. During conditioning, the animals received $30 \mathrm{~min}$ of access to $15 \mathrm{ml}$ of the compound solution, followed immediately by an i.p. injection of . $15 \mathrm{M} \mathrm{LiCl}$ solution $(10 \mathrm{ml} / \mathrm{kg}$ of body weight). On the next day, all animals received a recovery day, on which they were given free access to water for $30 \mathrm{~min}$ in the home cages. The groups were tested 1 day after the recovery session. The test lasted 2 days. During testing, all animals received 10 min of access to the compound solution. On the lst test day, half of the animals in each preexposure condition were tested in Context $A$, the context in which they had the preexposure experience with the flavors. The other half received the test in Context $B$, the context in which they had received tap water during preexposure. On the 2 nd test day, all animals were tested in the alternative context.

\section{Results}

On each day of the water-deprivation schedule, all animals drank all of the water within $30 \mathrm{~min}$. They also drank all $15 \mathrm{ml}$ of the available fluid on preexposure days. There was no difference in the consumptions of the solutions in Contexts A and B. On the conditioning day, all animals drank the $15 \mathrm{ml}$ of the compound.

Figure 3 illustrates the mean consumption of the compound flavor on the 2 test days for the different groups. As the figure indicates, the effect of preexposure procedure on compound conditioned aversion appeared to depend on the context; that is, an attenuation of the latent inhibition effect following preexposure to the elements was found when preexposure and test were carried out in the same context. In contrast, the element preexposure group and the compound preexposure group showed an equivalent latent inhibition effect when preexposure and test were carried out in different contexts. This description of the results was confirmed by an ANOVA with preexposure as the between-subjects factor and context as a within-subjects factor. Although the analyses revealed no effect of context $[F(1,43)=3.18, p>.05]$, there was a significant effect of preexposure $[F(2,43)=43.85, p<.001]$, and importantly, a significant interaction between preexposure and context factors $[F(2,43)=3.27, p<.05]$.

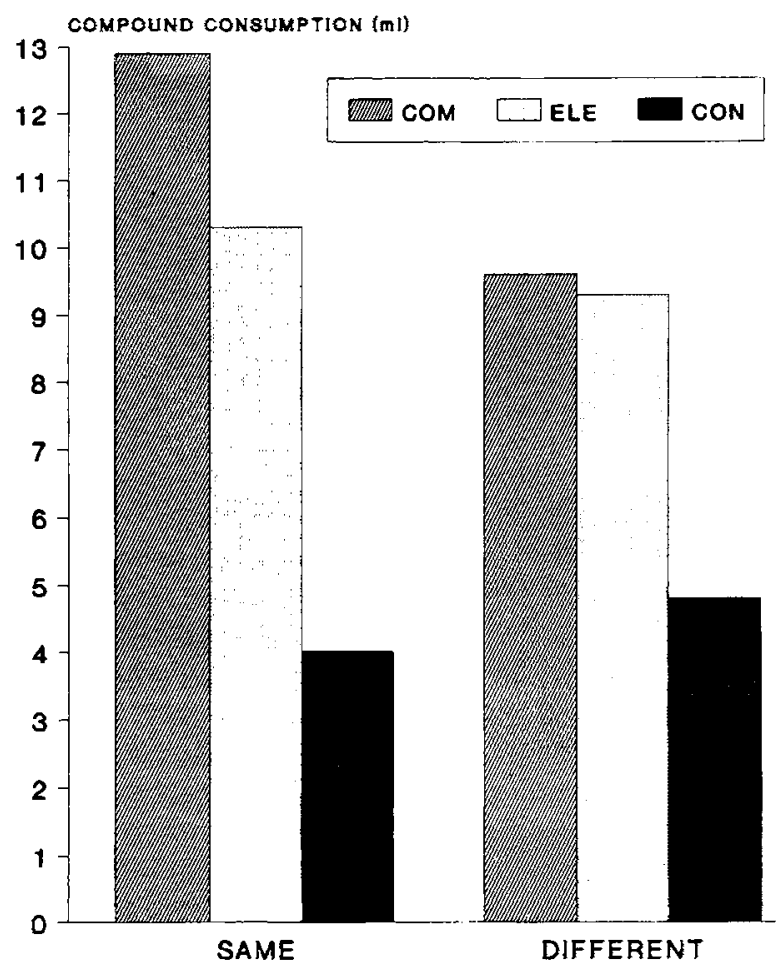

Figure 3. Experiment 3: Mean consumption of the compound flavor during test phase for each of the groups when tested in the preex posure context (same) or in the different context (different).

Individual group Newman-Keuls comparisons $(p<$ .05 ) revealed a significant difference between consumption by Groups COM and ELE when testing occurred in the same context as did preexposure. However, there was no significant difference between these groups when a context switch occurred between preexposure and testing. In all cases, the preexposed groups showed higher consumption than did control groups. A paired $t$ test also revealed that animals preexposed to the compound (Group COM) drank more when they were tested in the preexposure context than they did when tested in the alternative context $[t(14)=2.75, p<.05]$. However, animals in the control groups (Group CON) showed similar consumption in Contexts $\mathrm{A}$ and $\mathrm{B}$, as did animals in the element preexposure groups $[t(14)=0.80, p>.05$, and $t(14)=$ $1.10, p>.05$, respectively].

\section{Discussion}

Two main findings were obtained in this experiment. First, preexposure to a compound flavor produced more latent inhibition than did preexposure to the elements separately when animals were tested in the preexposure context. This result is consistent with those of Experiments 1 and 2 when a short retention interval was used. Second, the two preexposure procedures yielded similar latent inhibition when the context was switched between preexposure and test. The latter finding is especially pertinent, 
because, contrary to Bouton's retrieval view of latent inhibition, a context switch resulted in attenuated latent inhibition only in the compound preexposure group. That is, when animals were preexposed to the compound in Context A and tested in Context B, they drank less of the compound solution than they did when preexposed and tested in the same context. However, the same phenomenon did not occur in the element preexposure condition. According to Bouton's account, the element preexposure treatment should produce a comparable effect-that is, an attenuation of latent inhibition--when preexposure and test are carried out in different contexts. Our data do not support this prediction.

\section{GENERAL DISCUSSION}

The findings of the present series of experiments confirm and extend previous results suggesting that the effects of nonreinforced stimulus preexposure in a conditioned taste aversion procedure can be influenced by context and retention interval. Experiments 1 and 2 demonstrated that in flavor-aversion learning with a compound flavor as the CS, preexposure to the elements of a compound produced less latent inhibition than did preexposure to the compound itself when a 1-day retention interval occurred between preexposure and conditioning (Experiment 1) or between conditioning and test phases (Experiment 2). On the other hand, preexposing the elements or the compound resulted in equivalent latent inhibition effects when a 21 -day retention interval was used. Thus, an interactive effect of preexposure procedure and retention interval appears to have occurred. In Experiment 3, preexposure to the compound flavor or to its separate clements yielded a similar latent inhibition effect when the context was changed from preexposure to testing. Thus, as has been found with other interference paradigms (see Bouton, 1991, 1993), the present experiments suggest that manipulations of both the background contextual stimuli and the retention interval affect performance in latent inhibition.

The retrieval-based account of latent inhibition assumes that the preexposure and conditioning experiences are represented independently in memory, and that at the time of testing the memory of preexposure interferes with retrieval of the conditioning episode. This account can be applied to our results. Compound preexposure groups with a short preexposure-test interval have competing memories and display latent inhibition; element preexposure groups suffer less competition from the preexposure memory because of generalization decrement and thus show less latent inhibition. But if the preexposure-test interval is long. the memory trace of preexposure to the elements becomes more like that of compound preexposure, and an equivalent latent inhibition effect is observed following element or compound preexposure. That is exactly the result observed in Experiments $I$ and 2. The element preexposure treatment resulted in as much latent in- hibition as did the compound preexposure treatment with a short but not with a long retention interval.

However, to explain all the results of these two experiments, we must assume that the memory traces established during preexposure experience change with the passage of time and as a result, that generalization from preexposure to the testing or conditioning phase is increased. As already mentioned, increased generalization with increasing length of the training-test interval has been repeatedly found in different learning tasks (see, e.g., Gisquet-Verrier \& Alexinsky, 1986; Perkins \& Weyant, 1958; Thomas \& Burr, 1969; Thomas \& López, 1962). Like the prior findings, the present findings of an equivalent latent inhibition effect following preexposure to the elements or to the compound with a 21 -day retention interval appears to reflect forgetting of the detailed characteristics or attributes of preexposed stimuli over time. Consistent with this interpretation, López Ramirez and Aguado Aguilar (1992), using a procedure similar to that employed in the present studies, have obtained attenuated latent inhibition following separate preexposure to the elements of a compound stimulus with a short (4-h) but not with a relatively long $(48-h)$ preexposure-conditioning interval.

Our results are not consistent with Kraemer's findings (e.g., Kraemer \& Roberts, 1984) that a long retention interval between conditioning and testing reduces the effect of flavor preexposure on conditioned taste aversion. These authors proposed that the attenuated aversion following a short retention interval is a result of conflicting representations, established during preexposure and conditioning, competing for expression during the retention test. In ad. dition, they argued that as the retention interval is extended, the aversion acquired during conditioning by preexposed subjects can be expressed more easily. Although a release from latent inhibition with delayed testing has been frequently found with generalized preexposure (nonreinforced experience with a stimulus similar to the CS) by Kraemer \& Roberts (1984) and by Kraemer and Ossenkopp (1986), and with nonreinforced experience with the CS itself (Bakner et al., 1991; Kraemer et al., 1988: Kraemer \& Roberts, 1984), there is no evidence from Experiments 1 and 2 to support the retrieval view of latent inhibition mentioned above. Specifically, we found similar attenuated aversions in animals that were preexposed to the compound flavor and conditioned (Experiment 1) or tcsted (Experiment 2) either 1 day or 21 days later. Likewise strong conditioned aversions were expressed by the nonpreexposed groups tested after the 1-day and the 21 day retention intervals, although there was an apparent increase in the strength of the aversion with the long interval in Experiment 2.

Finally, the resuits of Experiment 3 could partially be accommodated by Bouton's retrieval account of latent inhibition (e.g., Bouton, 1991, 1993). On this view, contextual change, which has effects similar to those of increasing the retention interval, reduces the effect of nonreinforce- 
ment. In our third experiment, we found an attenuation of latent inhibition in the compound preexposure group when context was switched between preexposure and test, supporting Bouton. The same effect was not observed, however, in the element condition. Moreover, in Experiments 1 and 2, a 21 -day interval did not attenuate latent inhibition resulting from the compound preexposure. Thus, these findings appear to indicate that context and interval manipulations did not have the same effects in the present experiments. Likewise, in contrast to Bouton's account, other explanations (for reviews see Riccio et al., 1992; Riccio et al. 1984) have suggested that performance deficits after a retention interval, but not the disruption induced by contextual change, can be considered as a memoryretrieval failure (Ackil, Carman, Bakner, \& Riccio, 1992; Gisquet-Verrier \& Alexinsky, 1986). The findings in the present experiments provide a clear demonstration of how different retention intervals can produce quite different outcomes. They appear to indicate that manipulation of retention interval affected the generalized latent inhibition (preexposure with a stimulus similar to the CS), whereas a context switch only reduced the primary latent inhibition (preexposure to the CS itself).

In summary, the present experiments indicate that retention interval and context manipulations have important effects on performance in a latent inhibition paradigm. An account which includes perceptual and retrieval processes might well explain the context and time effects observed in these experiments. Our data indicate that on test, the memories of preexposure and conditioning are compared, and that generalization decrement decreases as retention interval increases. A retrieval view can make sense of the finding that latent inhibition does not decrease with long retention intervals, but it requires rejection of the assumption that the memory of nonreinforced exposure is less retrievable with time than the memory of conditioning episode.

\section{REFERENCES}

Ackil, J. K., Carman, H. M., Bakner, L., \& Riccio, D. C. (1992). Reinstatement of latent inhibition following a reminder treatment in a conditioned taste aversion paradigm. Behavioral \& Neural Biology, 58, 232-235.

Álvarez Gómez, R., \& López Ramírez, M. (1993). Latent inhibition to a compound following exposure to the elements or the compound. Bulletin of the Psychonomic Society, 31, 569-570.

Baker, A. G., Haskins, C. E., \& Hall, G. (1990). Stimulus generalization decrement in latent inhibition to a compound following exposure to the elements or the compound. Animal Learning \& Behavior, 18, 162-170.

Bakner, L., Strohen, K., Nordeen, M., \& Riccio, D. C. (1991). Postconditioning recovery from the latent inhibition effect in conditioned taste aversion. Physiology \& Behavior, 50, 1269-1272.

BATSELL, W. R., JR., \& BEST, M. R. (1992). Variations in the retention of taste aversions: Evidence for retrieval competition. Animal Learning \& Behavior, 20, 146-159.

Bouton, M. E. (1991). Context and retrieval in extinction and in other examples of interference in simple associative learning. In L. Dachowski \& C. F. Flaherty (Eds.), Current topics in animal learning: Brain, emotion and cognition (pp. 25-53). Hillsdale, NJ: Erlbaum. Bouton, M. E. (1993). Context, time, and memory retrieval in the in- terference paradigms of Pavlovian learning. Psychological Bulletin. 114, 80-99.

Bouton, M. E., \& Brooks, D. C. (1993). Time and context effects on performance in a Pavlovian discrimination reversal. Journal of Experimental Psychology: Animal Behavior Processes, 19, 165179.

Gisquet-VerRier, P., \& Al.exinsky, T. (1986). Does contextual change determine long-term forgetting? Animal Learning \& Behavior, 14 , 349-358.

Gordon, W. C., \& WEAVER, M. S. (1989). Cue-induced transfer of CS preexposure effects across contexts. Animal Learning \& Behavior, 17, 409-417.

Hall, G., \& Channell, S. (1985). Differential effects of contextual change on latent inhibition and on the habituation of an orienting response. Journal of Experimental Psychology: Animal Behavior Processes, 11, 470-481.

Hall, G., \& Mrnor, H. (1984). A search for context-stimulus associations in latent inhibition. Quarterly Journal of Experimental Psychology, 36B, 145-169.

HONEY, R. C., \& Hal., G. (1988). Overshadowing and blocking procedures in latent inhibition. Quarterly Journal of Experimental Psychology, 40B, 163-186.

HONEY, R. C., \& HALL, G. (1989). Attenuation of latent inhibition after compound preexposure: Associative and perceptual explanations. Quarterly Journal of Experimental Psychology, 41B, 351-368.

Kraemer, P. J., Hoffman, H., \& SPEAR, N. E. (1988). Attenuation of the CS-preexposure effect after a retention interval in preweanling rats. Animal Learning \& Behavior, 16, 185-190.

Kraemer, P. J., \& OSSFenkopp, K.-P. (1986). The effects of flavor preexposure and test interval on conditioned taste aversions in rats. Butletin of the Psychonomic Society, 24, 219-221.

Kraimer, P. J., Randall., C. K.. \& Carbary, T. J. (1991), Release from latent inhibition with delayed testing. Animal Learning \& Bcharior. 19, 139-145

Kraemer, P. J., \& Roberis, W. A. (1984). The influence of flavor preexposure and test interval on conditioned taste aversions in the rat. Learning \& Motivation, 15, 259-278.

Kraemer, P. J., \& SpFar, N. E. (1992). The effect of nonreinforced stimulus exposure on the strength of a conditioned taste aversion as a function of retention interval: Do latent inhibition and extinction involve a shared process? Animal Learning \& Behatior, 20, 1-7.

López Ramírez, M., \& aglado Agullar, L. (1992). Effects of eldment or compound preexposure on taste-aversion learning with simultaneous and serial compounds. Bulletin of the Psichonomic Society, 30, 279-282.

LUBOw, R. E. (1973). Latent inhibition. Psychological Bulletin. 79, 398407.

LuBow, R. E. (1989). Latent inhibition and conditioned attention theory. Cambridge: Cambridge University Press.

LUBOW, R. E., WeINER, I., \& SCHNUR, P. (1981). Conditioned attention theory. In G. H. Bower (Ed.), The psychology of learning and motivation (Vol. 15, pp. 1-49). New York: Academic Press.

MACKInTOSH, N. J. (1975). A theory of attention: Variations in the associability of stimuli with reinforcement. Psychological Review; 82. 276-298.

McINTOSH, S. M., \& TARPY, R. M. (1977). Retention of latent inhibition in a taste-aversion paradigm. Bulletin of the Psychonomic Society, 9. 411-412.

Pearce, J. M., \& Hall, G. (1980). A model for Pavlovian learning: Variations in the effectiveness of conditioned but not of unconditioned stimuli. Psychological Review, 87, 532-552.

Perkins, C. C., JR., \& WeYANT, R. G. (1958). The interval between training and test trials as determiner of the slope of generalization gradicnts. Journal of Comparative \& Physiological Psychology, 51, 596-600.

RESCORLA, R. A (1973). Evidence for the "unique stimulus" account of configural conditioning. Journal of Comparative \& Physiological Psychology, 85, 331-338.

Riccio, D. C., ACKIL, J., \& BurCh-Vernon, A. (1992). Forgetting of stimulus attributes: Methodological implications for assessing associative phenomena. Psychological Bulletin, 112, 433-445.

Riccio, D. C., Richardson, R., \& Ebner, D. L. (1984). Memory re- 
trieval deficits based upon altered contextual cues: A paradox. Psychological Bulletin, 96, 152-165.

SIEGEL, S. (1969). Generalization of latent inhibition. Journal of Comparative \& Physiological Psychology, 69, 157-159.

SPEAR, N. E. (1978). The processing of memories: Forgetting and retention. Hillsdale, NJ: Erlbaum.

Thomas, D. R. (1981). Studies of long-term memory in the pigeon. In N. E. Spear and R. R. Miller (Eds.), Information processing in animals: Memory mechanism.s (pp. 257-290). Hillsdale, NJ: Erlbaum.

Thomas, D. R., \& Burr, D. E. S. (1969). Stimulus generalization as a function of the delay between training and testing procedures: A reevaluation. Joumal of the Experimental Analysis of Behavior, 12, $105-109$.
Thomas, D. R., \& LóPez, L. J. (1962). The effect of delayed testing on generalization slope. Journal of Comparative \& Physiological PSychology, 44, 541-544.

WAGNER, A. R. (1978). Expectancies and the priming of STM. In S. H Hulse, H. Fowler, \& W. K. Honig (Eds.), Cognitive processes in animal hehavior (pp. 177-210). Hillsdale, NJ: Erlbaum.

WAGNER, A. R. (1981). SOP: A model of automatic memory processing in animal behavior. In N. E. Spear \& R. R. Miller (Eds.), Information processing in animals: Memory mechanisms (pp. 5-47). Hillsdale NJ: Erlbaum.

(Manuscript received October 11, 1993; revision accepted for publication October $3,1994$. ) 